\title{
Potential Complications of Helicobacter pylori Infection in Children of a Non-Urban Community
}

\author{
Abdelrazak M Ali ${ }^{1, *} ;$ Walid F Elkhatib ${ }^{2,3}$ \\ ${ }^{1}$ Department of Pediatrics, Faculty of Medicine, Al-Azhar University, Cairo, Egypt \\ ${ }^{2}$ Department of Microbiology and Immunology, Faculty of Pharmacy, Ain Shams University, African Union Organization St. Abbassia, Cairo, Egypt \\ 3 Department of Pharmacy Practice, School of Pharmacy, Hampton University, Hampton, USA \\ *Corresponding author: Abdelrazak M Ali, Department of Pediatrics, Faculty of Medicine, Al-Azhar University, Nasr City, Cairo 11787, Egypt. Tel:+20-226952482, E-mail: Dr.abdelrazak_ali@yahoo.com
}

Received: September 10, 2014; Revised: November 12, 2014; Accepted: January 8, 2015

\begin{abstract}
Background: Helicobacter pylori (H. pylori) is one of the most common chronic bacterial infections world-wide and has several adverse consequences particularly on health of pediatric patients.

Objectives: The current study addressed various clinical presentations associated with H. pylori infections among children of a rural community.

Materials and Methods: In this case-control study, the number of cases (H. pylori- positive) were 120 (52.5\% boys and $47.5 \%$ girls) and the control group (H. pylori-negative) were 100 cases aged $7-12$ years old (Mean $9.9 \pm 3$ years). H. pylori infection was defined by positive results for H. pylori stool antigen test and serum IgG or urea breath test. All pediatric participants were assessed for weight, height, sideropenic anemia and gastrointestinal symptoms.

Results: The results showed that recurrent abdominal pain, recurrent vomiting and anorexia were $81(67.5 \%), 24$ (20\%) and 15 (12.5\%), respectively in H. pylori-infected patients, compared to $28(28 \%), 8(8 \%)$ and $4(4 \%)$ in control group. Weight and height were $20.4 \pm 1 \mathrm{~kg}$ and $128.1 \pm 1 \mathrm{~cm}$ in case group compared to $25.6 \pm 1.7 \mathrm{~kg}$ and $133.8 \pm 2 \mathrm{~cm}$ in control group. Sideropenic anemia was $36.7 \%$ in patients compared to $15 \%$ in control.

Conclusions: In conclusion, the study findings revealed that pediatric $H$. pylori infection is associated with recurrent abdominal pain, anorexia and recurrent vomiting, also adversely affects the growth of children in various modalities; in particular weight, height and progressive incidence of sideropenic anemia.
\end{abstract}

Keywords: Helicobacter Pylori; Pediatrics; Signs and Symptoms, Digestive System; Anemia, Iron-Deficiency

\section{Background}

Helicobacter pylori (H. pylori) is a spiral or curved Gramnegative microaerophilic and flagellated bacillus. Such bacteria selectively colonize the mucus layer of the human stomach and in area of gastric metaplasia in the duodenum and Barrett esophagus. Furthermore, this organism represents the major cause of chronic gastritis, gastric ulcer, duodenal ulcer, gastric lymphoma and gastric adenocarcinoma (1). H. pylori is a common pathogen with prevalence rates of more than $80 \%$ in developing countries and less than $40 \%$ in developed countries (2).

H. pylori infection is common in pediatric patients and the organism represents the most prevalent gastric microbial pathogen (3). Individuals infected with H. pylori have $10-20 \%$ lifetime risk of developing peptic ulcer and have 1 - 2\% lifetime risk of acquiring stomach cancer (2, 4). Moreover, elevated gastric Mucosa-Associated Lymphoid Tissue (MALT) lymphoma has been linked to H. pylori infection, because early eradication of this infection in low grade tumors leads to complete remission (5).
H. pylori produces different virulence factors including urease (base of urea breath test), vacuolating cytotoxin, catalase and lipopolysaccharide (LPS). Urease is a potent antigen, which induces IgG and IgA production (6). Catalase supports $H$. pylori survival in the host by preventing the formation of reactive oxygen metabolites from hydrogen peroxide. The LPS outer membrane of $H$. pylori enhances the ability of organism to colonize the stomach (6). Serological detection of $H$. pylori IgG antibodies is crucial in the assessment of children with recurrent abdominal pain and other gastrointestinal symptoms (7). Children represent an ideal population for studying the consequences and complications of $H$. pylori infection, because pediatrics have no common causes of secondary gastrointestinal diseases such as drugs, tobacco and alcohol (3). Furthermore, H. pylori associated diseases can be controlled and treated effectively by early eradication of the bacterium (6).

Recently, potential associations between $H$. pylori infection and other gastric diseases such as gastroesopha-

Copyright (C) 2015, Pediartric Infections Research Center. This is an open-access article distributed under the terms of the Creative Commons Attribution-NonCommercial 4.0 International License (http://creativecommons.org/licenses/by-nc/4.0/) which permits copy and redistribute the material just in noncommercial usages, provided the original work is properly cited. 
Ali AM et al.

geal reflux disease (GERD) as well as several extra-gastric pathologies (e.g. asthma, growth retardation and chronic idiopathic thrombocytopenic purpura) have been postulated, but such findings are still paradoxical between different studies (8).

\section{Objectives}

The purpose of this study was to investigate the association between $H$. pylori infection and gastrointestinal symptoms as well as non-gastrointestinal complications such as growth retardation and sideropenic anemia in children from a non-urban community.

\section{Materials and Methods}

Approval of this study was received from the administration of Al emeis National Hospital, Saudi Arabia. Routine consents for laboratory diagnosis were implemented for all cases according to hospital regulations and the study protocol conformed to the ethical guidelines of the 1975 Declaration of Helsinki. The study was conducted in Gazan District (a non-urban region in Saudi Arabia) and enrolled 220 human subjects divided into two groups; H. pylori-positive (Case) group $(\mathrm{n}=120)$ was defined by positive documentation of at least two of the three laboratory test results (H. pylori stool antigen, UBT and serology) and H. pylori-negative (Control) group (n $=100$ ) with negative laboratory tests for H. pylori (both urea breath test (UBT) and $H$. pylori stool antigen test). All participants were clinically examined for the presence of gastrointestinal symptoms including Recurrent Abdominal Pain (RAP), recurrent vomiting and chronic anorexia for three months. For all pediatric participants, weight and height were documented in this study. Referral criteria to the RAP clinic were (a) age between 7 and 12 years, (b) Apley's criteria of unexplained abdominal pain, severe enough to interfere with daily activities and occurring at least three times in the preceding three months (9).

Patients with hematologic disorders (e.g. sickle cell anemia), immunologic or metabolic disorders, food allergy (celiac disease), collagen vascular diseases or children receiving antibiotics for last four weeks or receiving antisecretory therapy for last two weeks, as well as patients with past or family history of psychic element were all excluded from this study. All cases ( 7 - 12 years) were relatively matched with eligible control group for age, sex, race, maternal age, education and other sociodemographic variables to rule out any possible confounders.

\subsection{Detection of H. pylori Infection}

H. pylori infection was laboratory diagnosed through H. pylori stool antigen test as well as anti-H. pylori antibodies test (ELISA) or the urea breath test (UBT).

\subsection{H. pylori Stool Antigen Test}

Fecal specimens were examined using the stool antigen test (One step H. pylori antigen test device; ACON Laboratories Inc., San Diego, CA, USA) according to the manufacturer's directions. H. pylori stool antigen test is considered as a flow Immunoassay reaction using polyclonal antibodies. In brief, collected stool samples were transferred to vials with the extraction fluid, vigorously agitated and left for two minutes for settling of suspended particulates. Two to three drops were then transferred into the circular port hole of the test cassette and results were recorded after 10 minutes of incubation at room temperature. Depending on the development of colored lines across the cassette, simultaneous appearance of two lines (control and test) indicates positive $H$. pylori infection. On the other hand, appearance of only one line in the control section indicates negative $H$. pylori infection.

\subsection{Anti-H. pylori Antibodies Test}

Individuals infected with $H$. pylori develop antibodies that significantly correlate with histologically confirmed $H$. pylori infection. Moreover, there is a good correlation between ELISA antibody test and rapid urease test, which afford confirmatory diagnosis of $H$. pylori infection $(10,11)$. In this study, serum samples were assessed through ELISA for the presence of anti-H. pylori IgG antibodies against high molecular weight cell-associated protein (HM-CAP) of $H$. pylori using the HM-CAP ELISA kit (EZ-EM Inc., Westbury, NY, USA) as described previously (12).

\subsection{Urea Breath Test (UBT)}

UBT was performed for practically cooperative child who could swallow the medication (for case group, 104 of 120 patients were able to perform the test and for control group, 90 of 100 controls were able to do the test). The sensitivity and specificity of UBT are approximately 88 - 95\% and $95-100 \%$, respectively. False positive results are uncommon. False negative results may be observed in patients who receive antisecretory therapy, proton pump inhibitors (PPIs), bismuth or antibiotics. Therefore, the patient should be off antibiotics for at least four weeks and off PPIs for at least two weeks. The control group was defined by both negative $H$. pylori stool antigen test and UBT. The patients should be fasting at least two hours before performing BreathTek® UBT (Meretek Diagnostics Inc., Rockville, MD, USA). The test is suitable for epidemiologic studies, in any clinical condition where endoscopy is not required and for assessing the efficacy or eradication therapy. The diagnostic component of BreathTek® UBT kit is 13C-urea, a synthetic non-radioactive urea contained in a granulated powder for reconstitution with potable water to provide a clear solution for oral administration. An average adult body 
Ali AM et al.

normally contains about nine grams of urea, which is a product of protein metabolism. Urea in the body is referred to natural isotopic abundance urea (98.9\% 12Curea and 1.1\% 13C-urea). Pranactin-Citric product is a component of the BreathTek® UBT Kit (Meretek Diagnostics Inc.). According to manufacturer's instructions, three grams of reconstituted Pranactin-Citric containing $75 \mathrm{mg}$ of 13C-urea was ingested by patient. In the presence of gastric $H$. pylori urease, 13C-urea decomposes to $13 \mathrm{CO}_{2}$ and $\mathrm{NH} 4$. The $13 \mathrm{CO}_{2}$ is absorbed in the blood and then exhaled in the breath. The breath samples were collected and analyzed by UBiTß-IR300 Infrared spectrophotometer (Photal Otsuka Electronics Co., Japan). The positive results showed an increase in the ratio of $13 \mathrm{CO}_{2}$ to $12 \mathrm{CO}_{2}$ in a post-dose breath sample compared to a baseline sample taken before consumption of $13 \mathrm{C}$ urea solution. Delta over baseline (DOB) value of $\geq 2.4$ is interpreted as diagnostically positive indicating the presence of urease, which is associated with $H$. pylori infection. A DOB value of $<2.4$ is interpreted as diagnostically negative sample as reported previously (13).

\subsection{Iron Deficiency Anemia}

Serum samples of the pediatric participants were evaluated for ferritin to document iron deficiency (serum ferritin level $<22.47 \mathrm{pmol} / \mathrm{L}$ ) as well as anemia (hemoglobin level < 115 g/L) as described previously (14).

\subsection{Statistical Analysis}

T-test and Chi-square were used for data analysis. Odd ratios (the increased odds of getting a disease with exposure to risk factor versus non exposure to that factor) and confidence interval with 95\% were calculated. Data analyses in the current study were performed through SPSS, version 18.0 (SPSS Inc., Armonk, NY, USA).

\section{Results}

$H$. pylori infections were defined basically by the presence of at least two positive laboratory results for $H$. pylori (H. pylori stool antigen test, serum anti-H. pylori antibodies and UBT). Concerning all pediatric participants, the lab results revealed that $H$. pylori-positive cases, 120 (54.5\%) were relatively higher than $H$. pylori-negative ones, 100 (45.5\%). The demographic characteristics of pediatric participants $(n=220)$ are shown in Table 1 . The prevalence of $H$. pylori infection is inversely proportional with socio-economic status represented by the parental annual incomes. Furthermore, $H$. pylori infection is more prevalent in older $65(54.2 \%)$ and male patients 68 (56.7\%) than younger $55(45.8 \%)$ and female patients 52 (43.3\%), respectively (Table 1). From clinical point of view, recurrent abdominal pain, recurrent vomiting and anorexia were significantly $(\mathrm{P}<0.01)$ higher in $\mathrm{H}$. pylori infected (Case) group [81 (67.5\%), 24 (20.0\%) and 15 (12.5\%)] as compared to that in H. pylori non-infected (Control) group [28 (28.0\%), 8 (8.0\%) and $4(4.0 \%)]$, respectively (Figure 1).

In the current study, all cases were assessed for weight, height and sideropenic anemia. The results revealed that the averages of weight and height were significantly $(\mathrm{P}<0.01)$ lower in case group $(20.4 \pm 1.1 \mathrm{~kg}$ and $128.1 \pm 1.0 \mathrm{~cm})$ compared to control group $(25.6 \pm 1.7 \mathrm{~kg}$ and $133.8 \pm 2.3 \mathrm{~cm}$ ), respectively. On the other hand, sideropenic anemia was significantly higher in case group (36.7\%) compared to control group (15.0\%) as shown in Table 2. Various risk parameters including relative risk, absolute risk increase, relative risk increase, odds ratio and attributable-risk percent are summarized in Table 3. Interestingly, the odds ratios $(>1.0)$ revealed significant associations between occurrence of events (i.e. recurrent abdominal pain, recurrent vomiting, anorexia and sideropenic anemia) in exposed group (H. pyloripositive) compared to non-exposed group (H. pylori-negative). Results of $H$. pylori laboratory tests for the study groups are summarized in Table 4.

Table 1. Demographic Characteristics of Pediatric Participants $(\mathrm{n}=220)$ Categorized as H. pylori-Positive (Case) and H. pyloriNegative (Control) Groups ${ }^{\text {a, }} \mathrm{b}$

\begin{tabular}{|c|c|c|}
\hline \multirow[t]{2}{*}{ Characteristics } & \multicolumn{2}{|c|}{$\begin{array}{l}\text { Groups of Partici- } \\
\text { pants }\end{array}$} \\
\hline & $\begin{array}{c}\text { Case } \\
(\mathbf{n}=\mathbf{1 2 0})\end{array}$ & $\begin{array}{r}\text { Control } \\
(\mathbf{n}=100)\end{array}$ \\
\hline \multicolumn{3}{|l|}{ Age, y } \\
\hline $7-10$ & $55(45.8)$ & $45(45.0)$ \\
\hline $10-12$ & $65(54.2)$ & $55(55.0)$ \\
\hline \multicolumn{3}{|l|}{ Gender } \\
\hline Male & $68(56.7)$ & $58(58.0)$ \\
\hline Female & $52(43.3)$ & $42(42.0)$ \\
\hline \multicolumn{3}{|l|}{ Child race } \\
\hline Saudi Arabian & $105(87.5)$ & $90(90.0)$ \\
\hline Non-Saudi Arabian & $15(12.5)$ & $10(10.0)$ \\
\hline \multicolumn{3}{|l|}{ Insurance } \\
\hline Medicaid & $88(73.3)$ & $75(75.0)$ \\
\hline Private, Cash & $32(26.7)$ & $25(25.0)$ \\
\hline \multicolumn{3}{|c|}{$\begin{array}{l}\text { Total annual income (calculated as } \\
\text { USD) }{ }^{\mathrm{C}}\end{array}$} \\
\hline$<30000$ & $72(60.0)$ & $58(58.0)$ \\
\hline $30000-50000$ & $21(17.5)$ & $16(16.0)$ \\
\hline $51000-100000$ & $15(12.5)$ & $11(11.0)$ \\
\hline$>100000$ & $12(10.0)$ & $15(15.0)$ \\
\hline $\begin{array}{l}\text { a Abbreviation: USD, US } \\
\text { b Data are presented as } N \\
\text { c Socioeconomic status } \\
\text { was almost balanced am } \\
\text { considering the rural nat }\end{array}$ & pation anc & $\begin{array}{l}\text { education } \\
\text { larly when }\end{array}$ \\
\hline
\end{tabular}




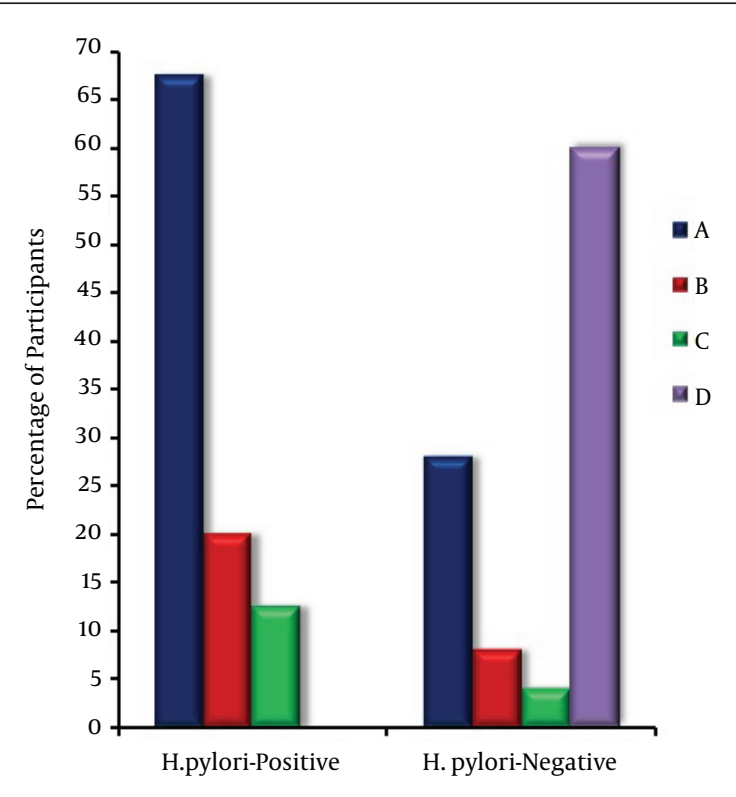

Figure 1. Diagrammatic Representation of Clinical Symptoms Including A) Recurrent Abdominal Pain, B) Recurrent Vomiting, C) Anorexia and D) Asymptomatic as Distributed in $\mathrm{H}$. pylori-positive (Case) and H. pylorinegative (Control) Groups.

Table 2. Distribution of Malnutrition Criteria Between Case and Control Groups of Pediatric Participants a, b

\begin{tabular}{|c|c|c|}
\hline \multirow{2}{*}{$\begin{array}{l}\text { Malnutrition Param- } \\
\text { eters }\end{array}$} & \multicolumn{2}{|c|}{ Groups of Participants } \\
\hline & Case $(n=120)$ & Control $(n=100)$ \\
\hline Weight average (S.E) & $20.4 \pm 1.1$ & $25.6 \pm 1.7$ \\
\hline Height average (S.E) & $128.1 \pm 1.0$ & $133.8 \pm 2.3$ \\
\hline Sideropenic anemia & $44(36.7)$ & $15(15.0)$ \\
\hline
\end{tabular}

\section{Discussion}

It is currently estimated that about a half of the world's population is infected with $H$. pylori. However, the prevalence of $H$. pylori is heterogeneous worldwide; it differs depending on patient's chronologic age, country of origin, ethnicity and socioeconomic conditions during childhood (15).H. pylori exploits and manipulates innate and adaptive immune cell signaling pathways to establish persistent infection (16). Nevertheless, unless specific eradication therapy is provided, gastric infection persists for lifetime (17). H. pylori induces inflammatory cytokines including interleukin $\mathrm{lB}$, which has been linked to an increased risk of hypochlorhydria and gastric cancer in infected subjects (18). The potential role of $H$. pylori in non-gastrointestinal manifestations is essentially based on: (1) systemic effects that arise from local inflammation; (2) chronicity of $H$. pylori infection which may last for decades; and (3) induction of both local and systemic lesions as a result of persistent infection and subsequent production inflammatory cytokines (19).

Diagnosis of $H$. pylori can be achieved through invasive and noninvasive methods. Invasive methods, involving histology, culture and rapid urease, necessitate endoscopy to obtain gastric biopsies. These tests are relatively specific and sensitive, but their results can be significantly influenced by focal distribution of $H$. pylori within the stomach. Additionally, in the developing countries, endoscopy may be expensive and laboratory facilities may limit the capability of culturing the organism (12). On the other hand, noninvasive methods for diagnosis of Hpylori, based on the analysis of samples from breath (e.g.13C-urea breath test;13C-UBT), blood (e.g. detection of anti-H. pylori IgG antibodies through ELISA) or stool (e.g. H. pylori stool antigen; HpSA test), have been developed and efficiently used in diagnosis of $H$. pylori infection (20). It was reported that noninvasive tests such as 13C-UBT, H. pylori stool antigen and anti-H. pylori immunoglobulin G antibody

Table 3. Different Risk Parameters Based on Symptoms Occurrence in H. pylori-Positive Group Compared to H. pylori-Negative Group

\begin{tabular}{lccccc}
\hline Symptoms & \multicolumn{1}{c}{ Relative Risk Absolute Risk Increase Relative Risk Increase } & Odds Ratio & Attributable Risk Percent \\
\hline Recurrent abdominal pain & 2.41 & 0.395 & 1.41 & 5.35 & $58.5 \%$ \\
Recurrent vomiting & 2.50 & 0.120 & 1.50 & 2.87 & $60.0 \%$ \\
Anorexia & 3.13 & 0.085 & 2.13 & 3.41 & $68.0 \%$ \\
Sideropenic anemia & 2.47 & 0.217 & 1.45 & 3.29 & $59.4 \%$ \\
\hline
\end{tabular}

Table 4. H. pylori Laboratory Tests of the Study Groups ${ }^{\text {a }}$

\begin{tabular}{lcc}
\hline Laboratory Test $^{\mathrm{b}}$ & \multicolumn{2}{c}{ Positive Results } \\
\cline { 2 - 3 } & Case Group $(\mathbf{n}=\mathbf{1 2 0})$ & Control Group $(\mathbf{n}=\mathbf{1 0 0})$ \\
\hline H. pylori stool antigen & $112 / 120(93.3)$ & $0 / 100(0.0)$ \\
Urea Breath Test & $93 / 104(89.4)$ & $0 / 90(0.0)$ \\
Serology & $101 / 120(84.2)$ & $17 / 100(17.0)$ \\
\hline a Data are presented as No. (\%). & \\
$\mathrm{b}_{\text {H. pylori infection was diagnosed by various laboratory tests as evident in this table. }}$
\end{tabular}


Ali AM et al.

are relatively concordant and specific for the diagnosis of $H$. pylori infection $(21,22)$. Furthermore, UBT has excellent sensitivity and specificity in lab diagnosis of $H$. pylori as mentioned previously $(12,23)$. Additional to the patient compliance, noninvasive methods for the diagnosis of $H$ pylori are relatively rapid and inexpensive (12). Accordingly, laboratory diagnosis of $H$. pylori infection for pediatric patients from rural community in this study was performed using noninvasive methods including $H$. pylori stool antigen test, anti-H. pylori antibodies test and UBT.

It has been previously reported that there was a positive correlation between $H$. pylori antibodies and food allergy manifested by gastrointestinal symptoms (24). In the current study, the results revealed a statistically significant $(\mathrm{P}<0.01)$ positive correlation between $H$. pylori infection and gastrointestinal symptoms (recurrent abdominal pain, vomiting and chronic anorexia) and such results are consistent with that described previously by some investigators in Eastern Europe (11).

On the other hand, it was reported that H. pylori infection in India was not associated with recurrent abdominal pain (25). However, the small sample size of the later study limits drawing any firm conclusions in this respect. Despite similar socioeconomic status between $H$. pylori-positive and negative children, the cross-sectional study of a large number of 5-7-year old preschool and school children suggested that $H$. pylori infection (diagnosed by urea breath test) was associated in German children with growth delay, growth retardation or both (26). Similarly, it has been suggested that $H$. pylori was associated with short stature through mechanisms independent of poor living conditions (27).

The results of this study revealed that $H$. pylori infection had adverse effects on growth parameters (weight and height) of pediatric patients and such results are consistent with the hypothesis that $H$. pylori infection is one of the environmental factors capable of retarding the growth $(26,27)$. The current findings were also explored in other studies performed at different sociodemographic background such as Japan (28), Egypt (29) and Gambia (30). The study conducted by Thomas et al. in Gambia suggested that the effect of $H$. pylori infection on growth faltering was in early infancy and did not persist into later childhood (30). It has been reported that age at which this bacterium is acquired seems to influence the possible pathologic outcome of infection. People infected with it at an early age are likely to develop more intense inflammation that may be accompanied by atrophic gastritis with a higher subsequent risk of gastric ulcer, gastric cancer or both. Furthermore, pathogen acquisition at an older age brings different gastric alterations and more likely lead to duodenal ulcer (31). Although infections are usually acquired in early childhood in all countries, the higher prevalence of $H$. pylori infection among the elderly actually reflects the higher infection rates when they were children rather than infection at later ages (2). In the United States, the prevalence appears to be higher in African-American and Hispanic populations, which may be attributed to socioeconomic factors $(32,33)$.

The available evidence regarding $H$. pylori infection and its consequence on growth in pediatric patients is still controversial and different cross-sectional studies that addressed the presence or absence of such association have been reported (34-38). Such apparent discrepancy and controversial results between various studies may be attributed to the nature and setting of these studies, age, ethnicity and socioeconomic factors of the tested populations, as well as geographical differences and number of $H$. pylori-infected patients. In the current study, $H$. pylori infection was significantly $(\mathrm{P}<0.05)$ correlated with sideropenic anemia. Expectedly, the cumulative impacts of $H$. pylori on gastrointestinal tract may justify increased development of sideropenic anemia in patient group. Some studies support the role of $H$. pylori in the development of refractory iron deficiency anemia $(39,40)$. Sideropenic anemia was not previously associated with hematemesis or tarry stools, suggesting that long-standing $H$. pylori infection itself can cause anemia in the absence of active bleeding from the gastrointestinal tract (41).

On contrary to few reports (42), H. pylori infection in this study could be correlated with growth retardation in children. The potential biologic justification for this correlation may be attributed to the effect of H. pyloriassociated inflammation on gastric derived hormones (e.g. leptin and ghrelin) involved in controlling appetite and consequently growth outcome (43). Moreover, association between $H$. pylori infection and iron-deficiency anemia in this study may be explained based on (I) sequestration of iron due to gastric antral $H$. pylori infection i.e. altered iron bioavailability induced by chronic infection and inflammatory cytokines throughout $H$. pylori pathogenesis and (II) decreased non-heme iron absorption caused by hypochlorhydria (6).

This study demonstrated that gastric $H$. pylori infection, growth faltering and iron-deficiency anemia are substantially interrelated in pediatric patients. Infection with $H$. pylori in children is the initiator of vicious cycle of events that results ultimately in malnutrition and growth impairment with micronutrient deficiency. This must stimulate medical awareness of pediatricians about the seriousness and potential prevalence of $H$. pylori infection in the context of chronic gastrointestinal complaints, refractory iron-deficiency anemia and/or growth retardation in pediatric patients. Further collaborative studies with large sample sizes are required to confirm this finding on national, regional and international levels.

\section{Authors' Contributions}

The authors are equally contributed in this study and both of them approved the final revised version of this manuscript. 


\section{References}

1. Suerbaum S, Michetti P. Helicobacter pylori infection. $N$ Engl J Med. 2002;347(15):1175-86.

2. Kusters JG, van Vliet AH, Kuipers EJ. Pathogenesis of Helicobacter pylori infection. Clin Microbiol Rev. 2006;19(3):449-90.

3. Sabbi T, De Angelis P, Colistro F, Dall'Oglio L, di Abriola GF, Castro M. Efficacy of noninvasive tests in the diagnosis of Helicobacter pylori infection in pediatric patients. Arch Pediatr Adolesc Med. 2005;159(3):238-41.

4. Keck JW, Miernyk KM, Bulkow LR, Kelly JJ, McMahon BJ, Sacco F, et al. Helicobacter pylori infection and markers of gastric cancer risk in Alaska Native persons: a retrospective case-control study. Can J Gastroenterol Hepatol. 2014;28(6):305-10.

5. El-Mahallawy HA, Bahgat N, El-Din HM, Farag SA, Nouh A, El-Attar I. Hepatitis $C$ virus and its genotypes and Helicobacter pylori in pediatric non-Hodgkin's lymphoma: could there be a possible etiologic role? J Egypt Natl Canc Inst. 2004;16(2):114-22.

6. Noto JM, Peek RM, Jr. Helicobacter pylori: an overview. Methods Mol Biol. 2012;921:7-10.

7. D'Elios MM, Czinn SJ. Immunity, inflammation, and vaccines for Helicobacter pylori. Helicobacter. 2014;19 Suppl 1:19-26.

8. Pellicano R, Franceschi F, Saracco G, Fagoonee S, Roccarina D, Gasbarrini A. Helicobacters and extragastric diseases. Helicobacter. 2009;14 Suppl 1:58-68.

9. Senbanjo IO, Oshikoya KA, Njokanma OF. Helicobacter pylori associated with breastfeeding, nutritional status and recurrent abdominal pain in healthy Nigerian children. J Infect Dev Ctries. 2014;8(4):448-53.

10. Pronovost AD, Rose SL, Pawlak JW, Robin H, Schneider R. Evaluation of a new immunodiagnostic assay for Helicobacter pylori antibody detection: correlation with histopathological and microbiological results. J Clin Microbiol. 1994;32(1):46-50.

11. Janulaityte-Gunther D, Kucinskiene R, Kupcinskas L, Pavilonis A Labanauskas L, Cizauskas A, et al. The humoral immuneresponse to Helicobacter pylori infection in children with gastrointestinal symptoms. FEMS Immunol Med Microbiol. 2005;44(2):205-12.

12. Frenck RW, Jr., Fathy HM, Sherif M, Mohran Z, El Mohammedy H Francis W, et al. Sensitivity and specificity of various tests for the diagnosis of Helicobacter pylori in Egyptian children. Pediatrics. 2006;118(4):e1195-202.

13. Kodama M, Murakami K, Okimoto T, Fukuda Y, Shimoyama T, Okuda $\mathrm{M}$, et al. Influence of proton pump inhibitor treatment on Helicobacter pylori stool antigen test. World J Gastroenterol. 2012;18(1):44-8.

14. Fagan RP, Dunaway CE, Bruden DL, Parkinson AJ, Gessner BD. Controlled, household-randomized, open-label trial of the effect of treatment of Helicobacter pylori infection on iron deficiency among children in rural Alaska: results at 40 months. J Infect Dis. 2009;199(5):652-60.

15. Peek RM, Jr., Blaser MJ. Helicobacter pylori and gastrointestinal tract adenocarcinomas. Nat Rev Cancer. 2002;2(1):28-37.

16. Muller A, Oertli M, Arnold IC. H. pylori exploits and manipulates innate and adaptive immune cell signaling pathways to establish persistent infection. Cell Commun Signal. 2011;9(1):25.

17. Wroblewski LE, Peek RJ, Wilson KT. Helicobacter pylori and gastric cancer: factors that modulate disease risk. Clin Microbiol Rev. 2010;23(4):713-39.

18. El-Omar EM, Carrington M, Chow WH, McColl KE, Bream JH, Young HA, et al. Interleukin-1 polymorphisms associated with increased risk of gastric cancer. Nature. 2000;404(6776):398-402.

19. Pacifico L, Osborn JF, Tromba V, Romaggioli S, Bascetta S, Chiesa C. Helicobacter pylori infection and extragastric disorders in children: a critical update. World J Gastroenterol. 2014;20(6):1379-401.

20. Gatta L, Ricci C, Tampieri A, Vaira D. Non-invasive techniques for the diagnosis of Helicobacter pylori infection. Clin Microbiol Infect. 2003;9(6):489-96.

21. Bode G, Marchildon P, Peacock J, Brenner H, Rothenbacher D. Diagnosis of Helicobacter pylori infection in children: comparison of a salivary immunoglobulin $\mathrm{G}$ antibody test with the [(13)C] urea breath test. Clin Diagn Lab Immunol. 2002;9(2):493-5.

22. Choi J, Kim CH, Kim D, Chung SJ, Song JH, Kang JM, et al. Prospective evaluation of a new stool antigen test for the detection of
Helicobacter pylori, in comparison with histology, rapid urease test, (13)C-urea breath test, and serology. J Gastroenterol Hepatol. 2011;26(6):1053-9.

23. Kullavanijaya P, Thong-Ngam D, Hanvivatvong O, Nunthapisud P, Tangkijvanich P, Suwanagool P. Analysis of eight different methods for the detection of Helicobacter pylori infection in patients with dyspepsia. J Gastroenterol Hepatol. 2004;19(12):1392-6.

24. Corrado G, Luzzi I, Pacchiarotti C, Lucarelli S, Frediani T, Cavaliere $\mathrm{M}$, et al. Helicobacter pylori seropositivity in children with atopic dermatitis as sole manifestation of food allergy. Pediatr Allergy Immunol. 2000;11(2):101-5.

25. Bansal D, Patwari AK, Malhotra VL, Malhotra V, Anand VK. Helicobacter pylori infection in recurrent abdominal pain. Indian Pediatr. 1998;35(4):329-35.

26. Richter T, Richter T, List S, Muller DM, Deutscher J, Uhlig HH, et al Five- to 7-year-old children with Helicobacter pylori infection are smaller than Helicobacter-negative children: a cross-sectional population-based study of 3,315 children. J Pediatr Gastroenterol Nutr. 2001;33(4):472-5.

27. Ertem D, Pehlivanoglu E. Helicobacter pylori may influence height in children independent of socioeconomic factors.J Pediatr Gastroenterol Nutr. 2002;35(2):232-3.

28. Takahashi M, Kimura H, Watanabe K. Helicobacter pylori infection in patients with idiopathic short stature. Pediatr Int. 2002;44(3):277-80.

29. Mohammad MA, Hussein L, Coward A, Jackson SJ. Prevalence of Helicobacter pylori infection among Egyptian children: impact of social background and effect on growth. Public Health Nutr. 2008;11(3):230-6.

30. Thomas JE, Dale A, Bunn JE, Harding M, Coward WA, Cole TJ, et al. Early Helicobacter pylori colonisation: the association with growth faltering in The Gambia. Arch Dis Child. 2004;89(12):114954.

31. Kivi M, Tindberg Y. Helicobacter pylori occurrence and transmission: a family affair? Scand J Infect Dis. 2006;38(6-7):407-17

32. Smoak BL, Kelley PW, Taylor DN. Seroprevalence of Helicobacter pylori infections in a cohort of US Army recruits. Am J Epidemiol. 1994;139(5):513-9.

33. Everhart JE, Kruszon-Moran D, Perez-Perez GI, Tralka TS, McQuillan G. Seroprevalence and ethnic differences in Helicobacter pylori infection among adults in the United States.J Infect Dis. 2000;181(4):1359-63.

34. Sood MR, Joshi S, Akobeng AK, Mitchell J, Thomas AG. Growth in children with Helicobacter pylori infection and dyspepsia. Arch Dis Child. 2005;90(10):1025-8.

35. Suoglu OD, Gokce S, Saglam AT, Sokucu S, Saner G. Association of Helicobacter pylori infection with gastroduodenal disease, epidemiologic factors and iron-deficiency anemia in Turkish children undergoing endoscopy, and impact on growth. Pediatr Int. 2007;49(6):858-63.

36. Soylu OB, Ozturk Y. Helicobacter pylori infection: effect on malnutrition and growth failure in dyspeptic children. Eur J Pediatr. 2008;167(5):557-62.

37. Cherian S, Forbes D, Sanfilippo F, Cook A, Burgner D. Helicobacter pylori, helminth infections and growth: a cross-sectional study in a high prevalence population. Acta Paediatr. 2009;98(5):860-4

38. Gulcan M, Ozen A, Karatepe HO, Gulcu D, Vitrinel A. Impact of H. pylori on growth: is the infection or mucosal disease related to growth impairment? Dig Dis Sci. 2010;55(10):2878-86.

39. Annibale B, Capurso G, Delle Fave G. The stomach and iron deficiency anaemia: a forgotten link. Dig Liver Dis. 2003;35(4):288-95.

40. Sherman PM. Appropriate strategies for testing and treating Helicobacter pylori in children: when and how? Am J Med. 2004;117 Suppl 5A:30S-5S.

41. Kato S, Nishino Y, Ozawa K, Konno M, Maisawa S, Toyoda S, et al The prevalence of Helicobacter pylori in Japanese children with gastritis or peptic ulcer disease. J Gastroenterol. 2004;39(8):734-8.

42. Bravo LE, Mera R, Reina JC, Pradilla A, Alzate A, Fontham E, et al. Impact of Helicobacter pylori infection on growth of children: a prospective cohort study. J Pediatr Gastroenterol Nutr. 2003;37(5):614-9.

43. Blaser MJ, Atherton JC. Helicobacter pylori persistence: biology and disease. JClin Invest. 2004;113(3):321-33. 